Article

\title{
The Effect of Plasma Electron Temperature on the Surface Properties of Super-Hydrophobic Cotton Fabrics
}

\author{
Liyun Xu ${ }^{1,2}$, Yuling Lai ${ }^{2}$, Liu Liu ${ }^{2,3}$, Lili Yang ${ }^{4}{ }^{(}$, Ying Guo ${ }^{1,5, *}$, Xijiang Chang ${ }^{1,5}$, \\ Jianjun Shi ${ }^{1,5}$, Ruiyun Zhang ${ }^{2,3}$ and Jianyong $\mathrm{Yu}^{3}$ \\ 1 Department of Applied Physics, College of Science, Donghua University, Shanghai 201620, China; \\ gangsheng1989@126.com (L.X.); changxj@dhu.edu.cn (X.C.); jshi@dhu.edu.cn (J.S.) \\ 2 Key Laboratory of Textile Science and Technology, Ministry of Education, College of Textiles, \\ Donghua University, Shanghai 201620, China; hoppings@foxmail.com (Y.L.); llisatc@126.com (L.L.); \\ ryzhang@dhu.edu.cn (R.Z.) \\ 3 Innovation Center for Textile Science and Technology, Donghua University, Shanghai 201620, China; \\ yujy@dhu.edu.cn \\ 4 College of Materials Science and Engineering, Donghua University, Shanghai 201620, China; \\ liliyang@dhu.edu.cn \\ 5 Member of Magnetic Conflnement Fusion Research Center, Ministry of Education, Donghua University, \\ Shanghai 201620, China \\ * Correspondence: guoying@dhu.edu.cn; Tel.: +86-18017905808
}

Received: 18 December 2019; Accepted: 6 February 2020; Published: 10 February 2020

\begin{abstract}
The existing coating systems used for the preparation of super-hydrophobic surfaces are facing new challenges because the use of organic solvents and long-carbon-chain organic fluorine monomers is banned. In this article, the authors have proven that by using inductively coupled plasma-enhanced chemical vapor deposition (PECVD) with argon (Ar), which is a completely dry process, lauryl methacrylate (LMA) can produce a stable super-hydrophobic coating effect. The effect of electron temperature on the super-hydrophobicity of cotton fabrics is investigated in terms of water repellency, chemical composition, and surface morphology. It is found that the improvement in the hydrophobicity of cotton fabric is attributed to the deposition of alkyl and ester groups, and the formation of a micro-nano-structure on the surface of the fabric after plasma treatment. The electron temperature plays an important role in achieving the super-hydrophobicity of cotton fabrics. The plasma-enhanced coating may offer a safe and dry super-hydrophobic technique with diverse applications.
\end{abstract}

Keywords: electron temperature; cotton fabrics; super-hydrophobic; LMA; PECVD

\section{Introduction}

In recent years, research on natural fabrics with high hydrophobicity has attracted significant attention due to the unique characteristics of these fabrics, such as self-cleaning, anti-contamination, and anti-sticking [1]. Although cotton fibers have many advantages, such as softness, comfort, and widespread applicability [2], they cannot be employed in many areas, due to their high hydroxyl group content and hydrophilicity, which may reduce the mechanical properties of the materials and promote the growth of microorganisms (fungi, mold, and bacteria) [3]. Super-hydrophobicity, with a water contact angle (WCA) above $150^{\circ}$ and a sliding angle (SA) below $10^{\circ}$, demonstrates the self-cleaning performance of cotton fabrics, which is one of the most desirable textile properties of cotton fabrics for outdoor sports or medical clothing textiles [4,5]. The traditional method to obtain a super- hydrophobic 
surface is to follow the lotus leaf model, in which a low-surface-energy material is combined with a specific topographical micro-nano-hierarchical structure on the surface of the material to afford the material the ability of self-cleaning. The $-\mathrm{CH}$ and $-\mathrm{CO}$-groups are the main hydrophobic groups of the lotus leaf [6]. Cotton fabric is made of interlacing yarn, which is composed of interwoven cotton yarn with a diameter of 100-200 $\mu \mathrm{m}$. In addition, many inherent voids and veins with diameters ranging from 10 to $40 \mu \mathrm{m}$ are found among all cotton yarns. These interwoven yarns, veins, and voids lead to an inherently micro-scaled texture, which can be further decorated with secondary nanostructures and hydrophobic molecules to make it super-hydrophobic [7-9].

Conventionally, hydrophobic surfaces can be fabricated in two different ways: Physical surface modification and chemical deposition [10], such as electro-spinning [11], sol-gel technology [12], and plasma-enhanced chemical vapor deposition (PECVD) treatment [13]. Lauryl methacrylate (LMA), with low vinyl groups and a long alkyl chain, can greatly increase the hydrophobicity of the modified materials [14]. Bryuzgin et al. [15] used two types of chemical processes to graft LMA copolymers onto the surface of cotton fabric. The treated samples obtained good water-repellency, with a wetting angle of $162^{\circ}$, but they did not address the stability of the super-hydrophobic surface. Most of the existing works involve comprehensive processes and devices of high cost, which limit the practical applications of super-hydrophobic coatings in industry and engineering. PECVD treatment, because of its gas phase process, is widely adopted as no waste liquids are generated during the whole process. Moreover, this treatment can preserve most properties of the treated fabrics because the reaction only occurs on the surface of the fabric.

In the PECVD reaction chamber, neutral gas is ionized into ions, electrons, and reactive species. The chemical reactions in plasma and their interactions with the solid surface determine the composition of the deposited film and the surface morphology of the plasma-treated surface in PECVD. In the reaction chamber, the processing reaction between the plasma and the substrate is complicated, and the variations in plasma parameters can ultimately affect the characteristics of the deposited film in terms of its chemical composition and surface roughness [16]. Under such plasma parameters, the electron temperature should have large effects on the production of various radicals and charged particles, upon which material processing strongly depends [17]. Karakas [18] suggested that the temperatures of charged and neutral species in inductively coupled plasma (ICP) are important for studying the basic physical reactions of plasma chemistry. Sasaki et al. [19] noted that the non-uniformity of plasma parameters in the axial space depends mainly on the distance between the plasma source and the measurement position. Li et al. [20] discussed the distribution of the electron temperatures of different axial and radial positions. They also pointed out that studying the potential physical mechanism of ICP discharge is helpful in improving the source performance and practical applications. Therefore, the control of electron temperature is of crucial importance for material processing. In particular, to our knowledge, there are no works studying electron temperature by ICP-PECVD for material surface treatments. To better understand the effect of PECVD electron temperature on the plasma treatment of a material's surface, the process mechanism and parameter optimization of the PECVD treatment need to be further investigated.

In this paper, we report a technically simple PECVD method to deposit a super-hydrophobic film on cotton fabrics, aiming to find the relationship between the plasma electron temperature and hydrophobicity. The electron temperature of plasma in the reactor chamber was measured by a Langmuir probe and altered by adjusting the process position or the gas pressure. In addition, the graft reactions on the cotton fiber surface and free radical polymerization of the LMA monomers greatly enhanced the bond between the fiber and coating layer and the intensity of the layer, which ultimately leads to a high washing stability of plasma-treated cotton fabrics with proper electron temperatures.

\section{Experimental Procedure}

Desized, scoured, and double-knitted cotton fabrics (with a grammage of $210.85 \mathrm{~g} / \mathrm{m}^{2}$ and $100 \%$ cotton) were prepared with a size of $40 \mathrm{~mm} \times 50 \mathrm{~mm}$. Argon ( $\geq 99.999 \%$ ) gas was supplied by Shanghai 
Canghai Industry Gas Co., Ltd. The standard soapflake and LMA (97\%, CAS\#142-09-6) were purchased from the China Textile Institute of Science and Technology and SA Chemical Technology (Shanghai, China) Co., Ltd., respectively. All chemical reagents were used without further purification.

A schematic diagram of the plasma device, which was designed by an independent research institute, is shown in Figure 1a. The low-temperature plasma was generated by a pulsed inductively coupled plasma (ICP) device powered by a radio-frequency (RF) power supply (Model: CESER 1320, Advanced Energy, Denver, CO, USA) and a matching network (Model: VM5000W, Advanced Energy, Denver, CO, USA) with a frequency of $13.56 \mathrm{MHz}$. The reaction chamber is a hard glass cylinder (Custom-made from JJJ Vacuum Equipment Co. LTD, Shanghai, China), which can bear high temperatures with a size of $\Phi 120 \mathrm{~mm} \times 180 \mathrm{~mm} \times 1 \mathrm{~mm}$. A single coupling copper coil [Figure 1a] with a diameter of $6 \mathrm{~mm}$ was used in the external wall of the reaction chamber. Cotton fabrics were placed on the testbed, and a mixture gas of argon/LMA (30-225/4.5 sccm) was pumped into the chamber to treat the fabrics for $5 \mathrm{~min}$ at a radio-frequency (RF) power of $45 \mathrm{~W}$ with a duty cycle of pulse modulation of $25 \%$ [Figure 1b]. The electron temperature was changed by adjusting the process position or gas pressure. The process position and gas pressure can be adjusted by the height of the testbed $\left(\mathrm{h}=80 \mathrm{~mm}, \mathrm{~h}_{\text {test-bed }}=13-65 \mathrm{~mm}\right)$ and argon flow rate, respectively.

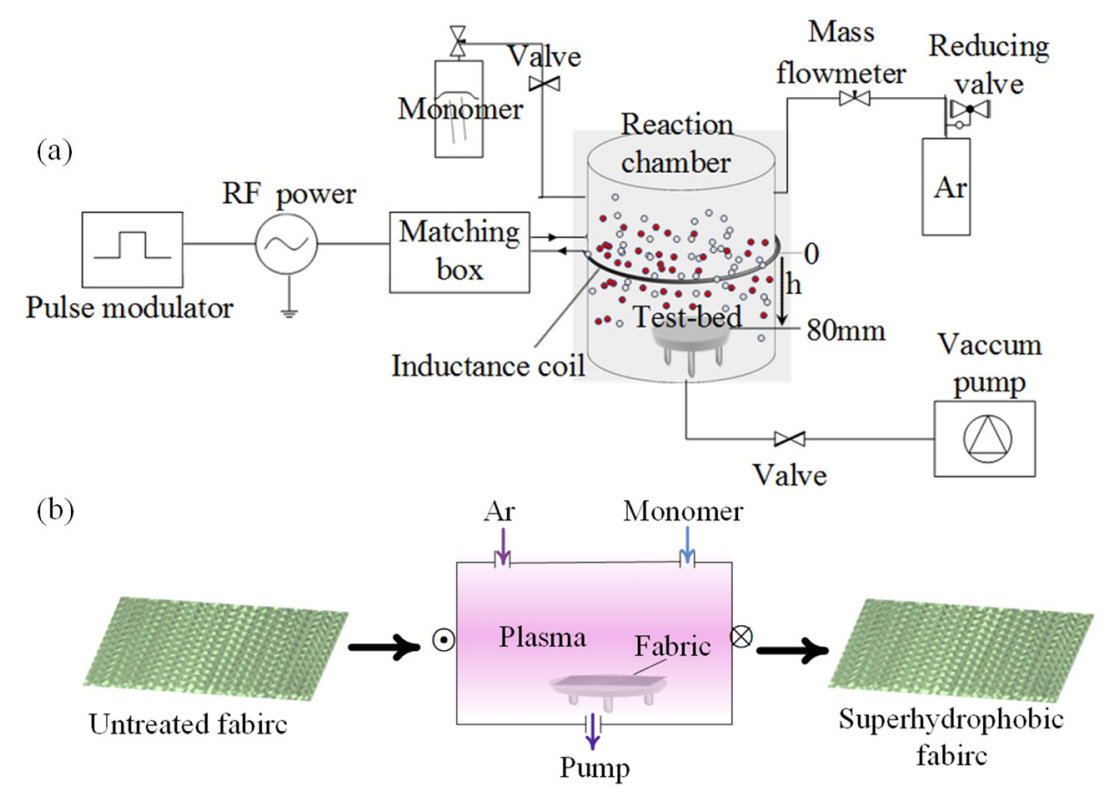

Figure 1. Schematic diagram of (a) the plasma reaction device and (b) the technological process of preparing the super-hydrophobic cotton fabric.

In this way, the electron temperatures in different process positions and under different pressures were measured by a Langmuir probe (MMLAB-probe 1, Dalian Polytechnic Changzhou Research Institute Co., Ltd., Changzhou, China) in argon plasma. We assumed that the electron temperature distribution function of the plasma obeys the Maxwell distribution law. The surface morphology of the control and plasma-treated cotton fabrics was measured by a scanning electron microscope (SEM, Hitachi S-4800, Hitachi, Tokyo, Japan) and an atomic force microscope (AFM, NanoScope ${ }^{\circledR}$ IIIa, Digital Instruments, Santa Barbara, CA, USA). X-ray photoelectron spectroscopy (XPS, Kratos AXIS UltraDLD, Daojin, Kyoto, Japan) was used to analyze the surface chemical compositions of the control and plasma-treated cotton fabrics. The water repellency of samples was characterized by WCA and SA at room temperature, with ambient humidities of 5 and $10 \mu \mathrm{L}$, respectively, on a DropMeter ${ }^{\mathrm{TM}}$ Professional A-200 instrument (Ningbo Haishu Mai Detection Technology co. LTD, Ningbo, China), equipped with a video camera. The washing durability of the fabric samples was evaluated with 
a water fastness testing machine (SW-8, Wenzhou Fangyuan Instrument co. Ltd., Wenzhou, China) according to GB/T 3921-2008, with the taken value based on the average of five tests.

\section{Results and Discussion}

\subsection{Water Repellency of Different Electron Temperatures}

The active particles in the ICP reaction chamber are generated near the coil and diffused around. The average electron temperature changes with the processing position and pressure. The electron temperature has a significant effect on the super-hydrophobicity of the plasma-treated cotton fabric surface (Figure 2a,b). Further, the process position plays a more significant role than gas pressure on the electron temperature. The best hydrophobicity (WCA $=160.95^{\circ}, \mathrm{SA}=9.01^{\circ}$, Video S1) for the plasma-treated cotton fabrics was achieved with an electron temperature of $4.46 \mathrm{eV}$ at a process position of $38 \mathrm{~mm}$ and a pressure of $25 \mathrm{~Pa}$. On the one hand, when the electron temperature was higher than $4.46 \mathrm{eV}$, the water repellency of the plasma-treated cotton fabric surface increased gradually with a decrease in the electron temperature (Figure 2a). On the other hand, when the electron temperature was lower than $4.46 \mathrm{eV}$, the water repellency of the plasma-treated cotton fabric surface was consistent with the changing trend of the electron temperature (Figure $2 b$ ). The dramatic change in electron temperature and contact angle around 48 to $60 \mathrm{~mm}$ was caused by the plasma sheath effect at the bottom of the chamber. Thus, in an ICP reaction chamber, the electron temperature in the plasma chamber determines the chemical and physical changes in the surface or near-surface layers of the cotton fabric, which affects the surface infiltration, cross-linking, and molecular weight [21-23].
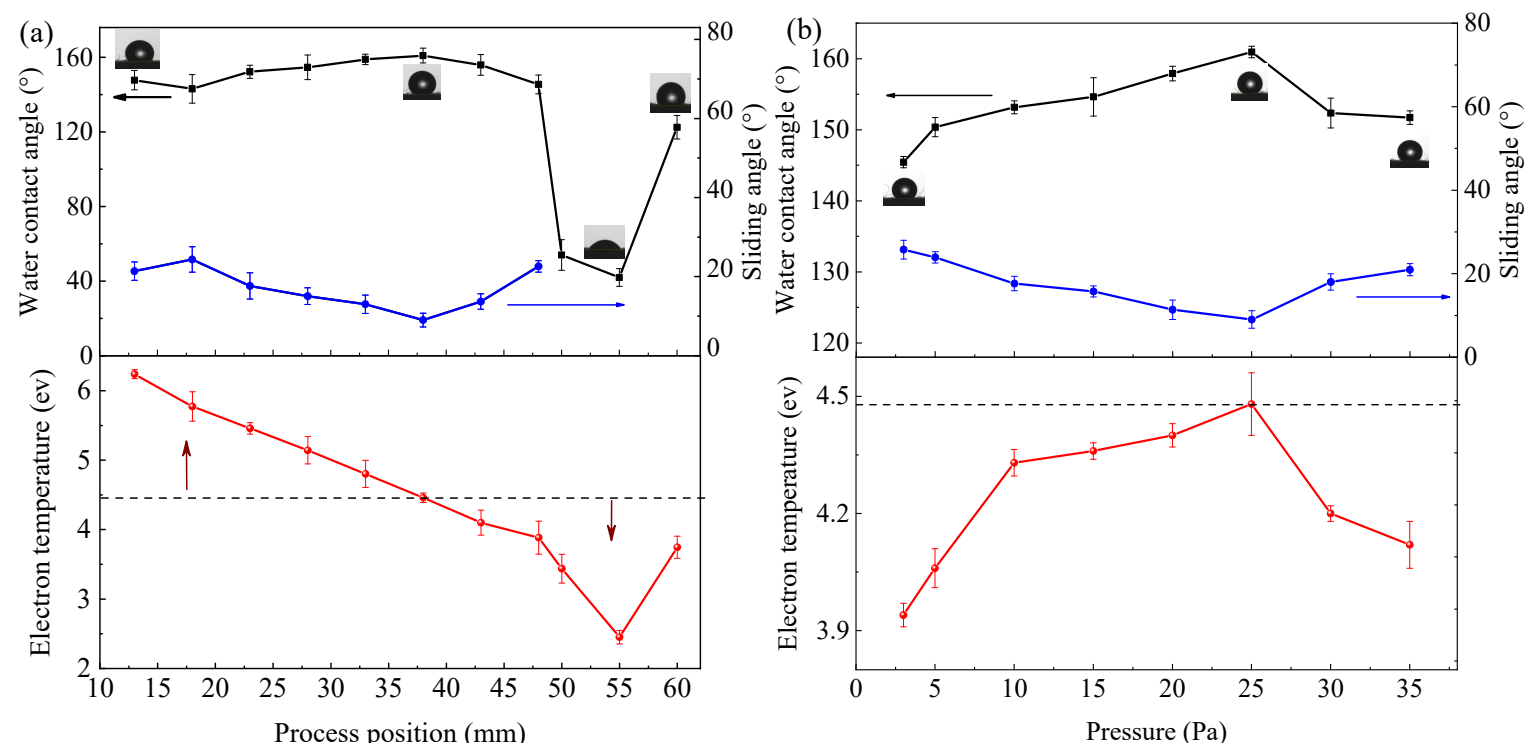

Figure 2. The change in the water repellency of cotton fabrics with different electron temperatures: (a) Process position and (b) pressure.

\subsection{Surface Morphology}

The key element for constructing a super-hydrophobic surface is a combination of low surface-energy materials and a specific-topography micro-nano-hierarchical structure [24]. The surface morphology and roughness of the plasma-treated cotton fabrics with different electron temperatures were measured and investigated to determine the differences in the water repellency of cotton fabrics (Figure 3). Figure 3a,e show that the untreated cotton fabrics exhibited a textured microscope fiber structure, with a relatively smooth surface. After plasma treatment, the thin-film coating appeared, and the roughness of the cotton fabric surface increased (Figure $3 b-d, f-h$ ). As shown in Figure $3 b, f$, when the electronic temperature was $6.24 \mathrm{eV}$, LMA film fragments appeared on the surface of the 
treated cotton fabric, and the surface roughness was relatively high, with relatively dense nanometer protrusions. According to Figure $3 c$, $g$, when the average electron temperature was $4.46 \mathrm{eV}$, the fibers were coated with thin films and had random distributions of micro-sized peaks and nano-sized protuberances after plasma treatment. However, when the electron temperature was $2.45 \mathrm{eV}$, the fibers' surfaces were clearly damaged (Figure $3 \mathrm{~d}$ ), and some trenches appeared at the nano- and micro-scales (Figure $3 \mathrm{~h}$ ). In the plasma process, thermal loading and plasma particle impacts can cause the direct removal of atoms, groups, and molecules from the substrate or deposition films [21]. In this way, the etching action causes the appearance of micro-size peaks, and the random deposition of LMA causes nano-sized protuberances on the surface of the cotton fabric.

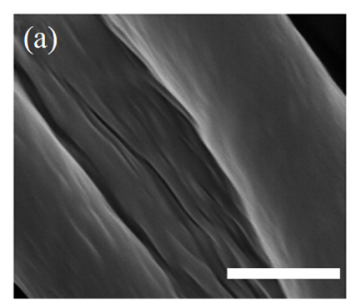

(e)

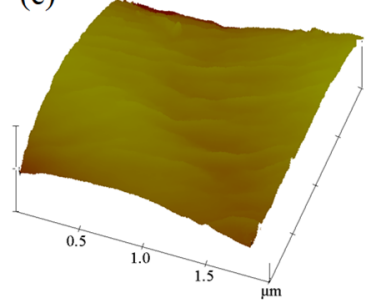

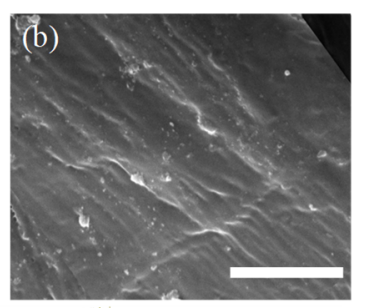

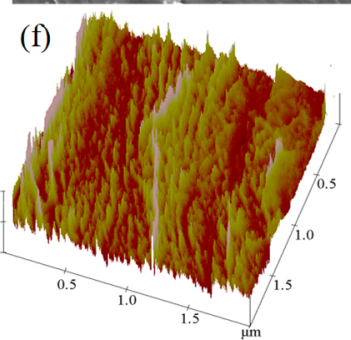

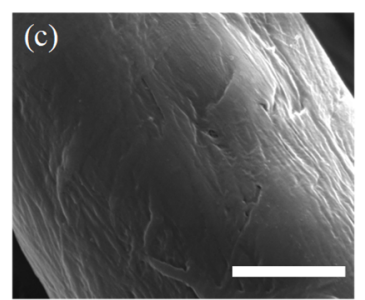

(g)

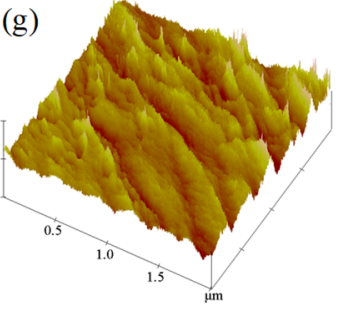

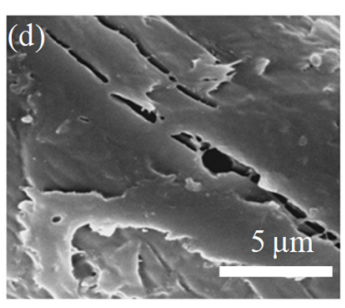

(h)

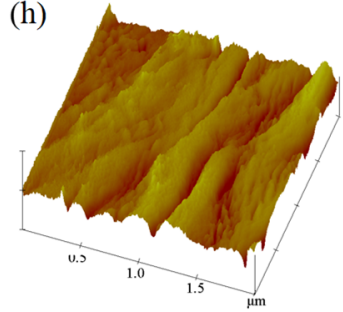

Figure 3. SEM and atomic force microscope (AFM) images of untreated (a,e) and modified cotton fabrics with electron temperature $=6.24(\mathbf{b}, \mathbf{f}), 4.46$, and $(\mathbf{c}, \mathbf{g}) 2.45 \mathrm{eV}(\mathbf{d}, \mathbf{h})$, respectively.

\subsection{Chemical Composition}

The typical bond dissociation energies and the results of the XPS test are shown in Table 1, Figure 4, and Table 2. According to Table 1, when the average electron temperature is too high $(6.24 \mathrm{eV})$, the effect of plasma on the material's surface is enhanced. Under the action of plasma, a large number of chemical bonds of LMA and the surface of the cotton fabrics were broken, resulting in a content increase of the $\mathrm{C}-\mathrm{C}$ bond and a content decrease of the $\mathrm{C}=\mathrm{O}$ and $\mathrm{C}-\mathrm{O}$ bonds on the surface of the cotton fabrics (Figure 4a and Table 2). Further, the content increase of the $\mathrm{C}-\mathrm{C}$ bond was the main chemical factor that improved the surface hydrophobicity of cotton fabrics.

According to Figure 4c, when the average electron temperature was $4.46 \mathrm{eV}$, the content of the $\mathrm{C}-\mathrm{C}$ bond and $\mathrm{C}=\mathrm{O}$ bond increased, while the content of the $\mathrm{C}-\mathrm{O}$ bond decreased. This indicates that the $\mathrm{C}-\mathrm{O}-\mathrm{H}$ bond of the cotton fabric was broken to form active sites, while the $\mathrm{C}=\mathrm{C}$ bond, $\mathrm{C}-\mathrm{C}$ bond, and $\mathrm{O}=\mathrm{C}-\mathrm{O}$ bond of the LMA molecule were decomposed into active particles. In the plasma reaction chamber, re-polymerization and a cross-linking reaction occurred between the active particles. Further, graft reactions of the active site on the cotton fabric surface existed in combination with the active particles. The increase in the alkyl and ester group was the chemical factor that caused the hydrophobicity increase on the surface of the cotton fabric.

According to Figure $4 \mathrm{~d}$, when the average electron temperature was too low $(2.45 \mathrm{eV})$, it was difficult for the active particles in the chamber to fully break the $\mathrm{C}-\mathrm{O}(3.61 \mathrm{eV})$ [25] bond on the surface of the cotton fabrics or the $\mathrm{C}-\mathrm{C}(3.74 \mathrm{eV})$ bond of the LMA. At this time, most of the gaseous LMA monomer was pumped out through the vacuum system. Only a small amount of LMA was absorbed on the surface of the cotton fabric. Therefore, when the electron temperature was $2.45 \mathrm{eV}$, the changes in the content of the chemical functional group on the surface of the treated sample were not as obvious as the control ones (Figure 4a). Furthermore, the irregular deposition of LMA on the surface of the 
cotton fibers increased the roughness of the cotton fiber surface and formed cracks (Figure 3d,h), which also caused a rapid reduction in the hydrophobicity of the cotton fabric surface.
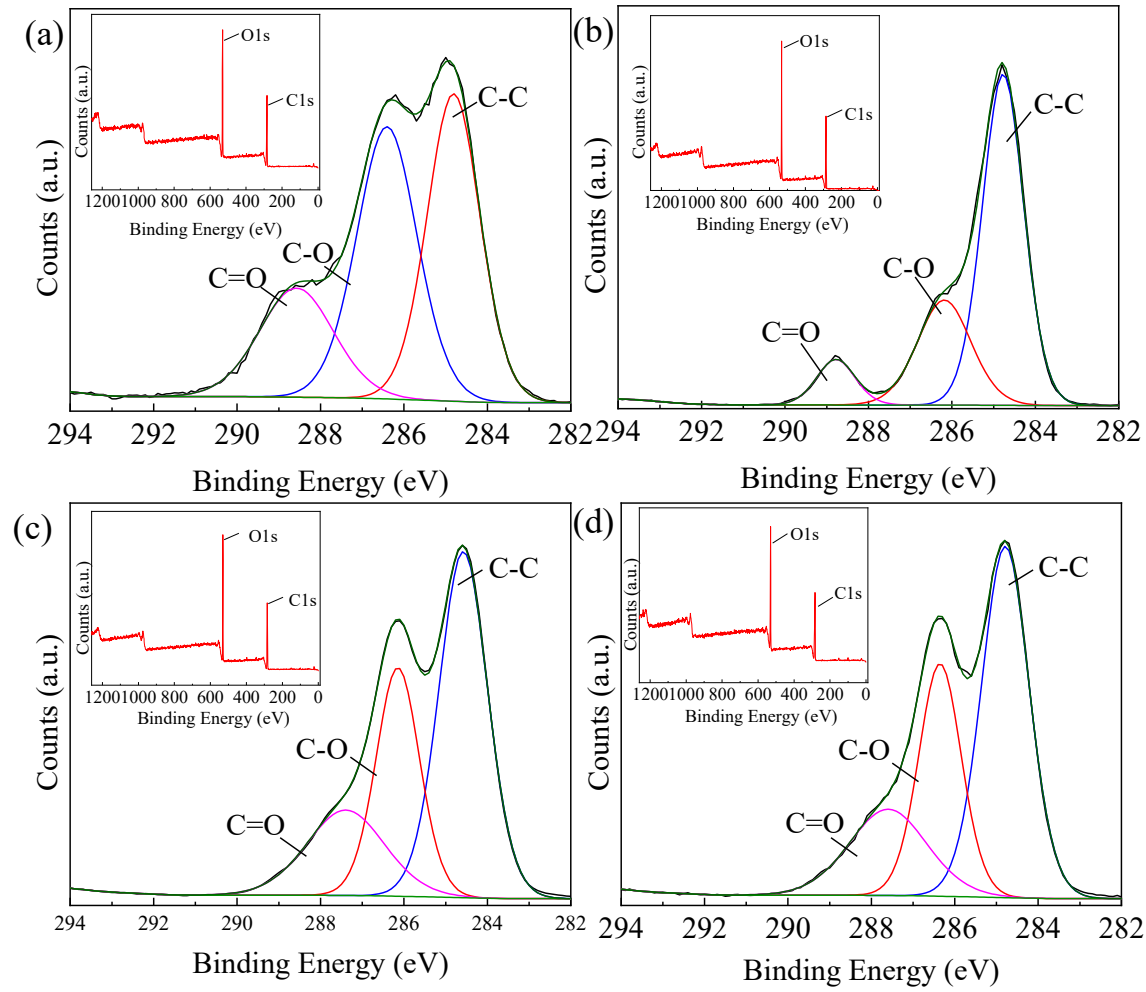

Figure 4. The XPS survey spectra and high-resolution Cls XPS spectra of the untreated (a) and modified cotton fabrics with electron temperature $=6.24(\mathbf{b}), 4.46(\mathbf{c})$, and $2.45 \mathrm{eV}(\mathbf{d})$.

Table 1. Typical bond dissociation energies [25].

\begin{tabular}{cc}
\hline Bond & Dissociation Energy $(\mathbf{e V})$ \\
\hline $\mathrm{C}=\mathrm{C}(\pi$ bond $)$ & 2.74 \\
$\mathrm{C}-\mathrm{C}$ & 3.61 \\
$\mathrm{C}-\mathrm{O}$ & 3.74 \\
$\mathrm{O}-\mathrm{H}$ & 4.83 \\
$\mathrm{C}=\mathrm{C}$ & 6.35 \\
$\mathrm{C}=\mathrm{O}$ & 7.78 \\
\hline
\end{tabular}

Table 2. An analysis of the high-resolution C1s XPS spectra of pristine and plasma-treated cotton fabrics.

\begin{tabular}{cccccc}
\hline \multirow{2}{*}{ Binding Energy (eV) } & \multirow{2}{*}{ Assignment } & \multicolumn{4}{c}{ Area (\%) } \\
\cline { 3 - 6 } & & Untreated & $\begin{array}{c}\text { Electron Temperature } \\
\mathbf{6 . 2 4} \mathbf{~ e V}\end{array}$ & $\begin{array}{c}\text { Electron Temperature }= \\
\mathbf{4 . 4 6} \mathbf{~ e V}\end{array}$ & $\begin{array}{c}\text { Electron Temperature = } \\
\mathbf{2 . 4 5} \mathbf{~ e V}\end{array}$ \\
\hline 284.8 & $\mathrm{C}-\mathrm{C}$ & 45.44 & 65.01 & 47.61 & 40.30 \\
286.3 & $\mathrm{C}-\mathrm{O}$ & 42.23 & 26.69 & 30.43 & 39.87 \\
287.8 & $\mathrm{C}=\mathrm{O}$ & 12.32 & 8.30 & 21.97 & 19.83 \\
\hline
\end{tabular}

\subsection{Washing Durability}

The corresponding washing durability of the cotton fabrics before and after plasma treatment, with electron temperatures of 6.24, 4.46, and $2.45 \mathrm{eV}$, was tested, and the results are shown in Figure 5. It was found that the properties of the washable fastness on the surface of the fabric after treatment at different electron temperatures were significantly different. When the electron temperature was $4.46 \mathrm{eV}$, the plasma-treated cotton fabric showed excellent water resistance (WCA $=151.28^{\circ}$ after 15 washes). However, when the electron temperature was 6.24 and $4.46 \mathrm{eV}$, the plasma-treated cotton fabric 
showed hydrophilicity $\left(\mathrm{WCA}=63.28^{\circ}\right)$ and superhydrophilicity $\left(\mathrm{WCA}<10^{\circ}\right)$ after 15 washing cycles. Notably, when the electron temperature was $2.75 \mathrm{eV}$, the water repellency and washing durability of the plasma-treated cotton fabrics were lower than those of the untreated cotton fabrics. Combined with the above surface morphology and chemical composition analysis, the structural integrity and chemical bonding of the LMA film on the surface of the fabric was the main factor used to improve the water repellency and washable performance of the cotton fabric's surface.

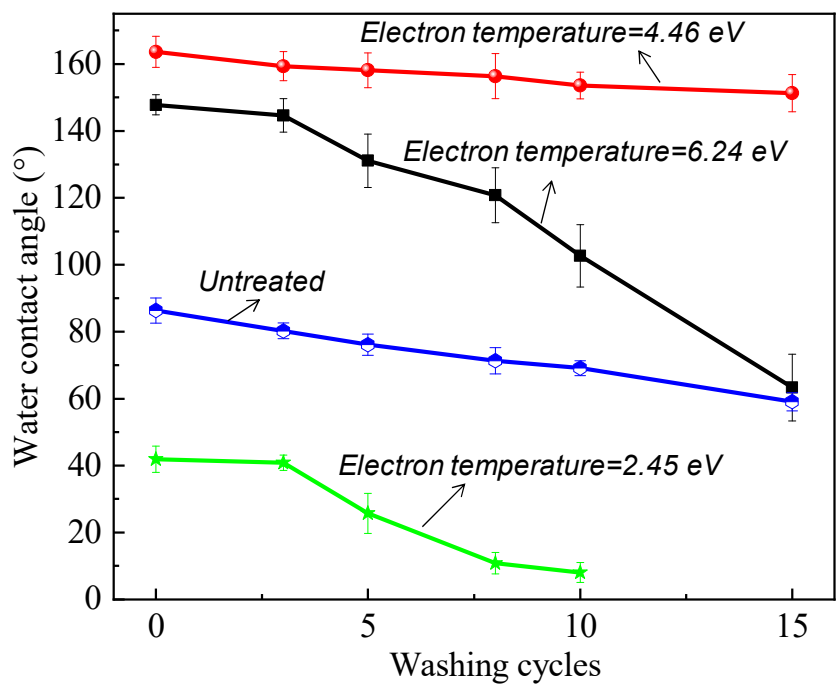

Figure 5. The curve of the water contact angle (WCA) washing cycles at different electron temperatures.

\subsection{Chemical Reaction Mechanism}

According to the XPS results, the possible reactions of the LMA-coated cotton fabric during the plasma treatment could be summarized, as shown in Figure 6. In the plasma reaction chamber, the argon and LMA monomer molecules were mixed first and then stimulated, ionized, aggregated, and developed quickly by the accretion of ions and radicals under the bombardment of the high-energy particles of plasma. Further, these active particles, such as free radicals, excited molecules, neutral molecules, ions, and energetic photons, acted on the surface of the cotton fabrics by radiation and collision via particle flux or ion beams and generated active sites on the surface of the cotton fabric and gas-phase free radicals in the chamber [26]. Under a proper average electron temperature $(4.46 \mathrm{eV})$, the molecular bonds of the cotton fibers and LMA were broken (cotton: $-\mathrm{C}-\mathrm{O}, \mathrm{C}-\mathrm{C}$, and $\mathrm{O}-\mathrm{H}$ bond; LMA: C-C, C=C, C-H, and C-O bond [26]). Small molecules like $\cdot\left(\mathrm{CH}_{2}\right)_{x}-\mathrm{CH}_{3}$ or $\cdot\left(\mathrm{CH}_{2}\right)_{n}-\mathrm{O}-\mathrm{CH}_{2}$. polymerized by free radicals (as shown in Figure 6a) were deposited on the surface of the cotton fabrics and formed chemical bonds with their active sites (like C-O or C-C. [7]), as shown in Figure 6b. Then, they reacted with the existing polymer and finally formed a chemically bonded LMA film on the surface of the fabrics. In summary, the radicals in the chamber induced graft reactions on the cotton fiber surface and free radical polymerization of the LMA monomers, which greatly enhanced the bond between the fiber and coating layer and the intensity of the layer. When the average electron temperature was too high $(6.24 \mathrm{eV})$ or too low $(2.45 \mathrm{eV})$, the growth and polymerization of free radicals on the surface of cotton fabrics were affected. In summary, only when the electron temperature was within a certain range could the radicals in the chamber induce graft reactions on the cotton fiber surface and free radical polymerization of LMA monomers, which greatly improved the water repellency of the surface and bonding between the fiber and coating layer. 


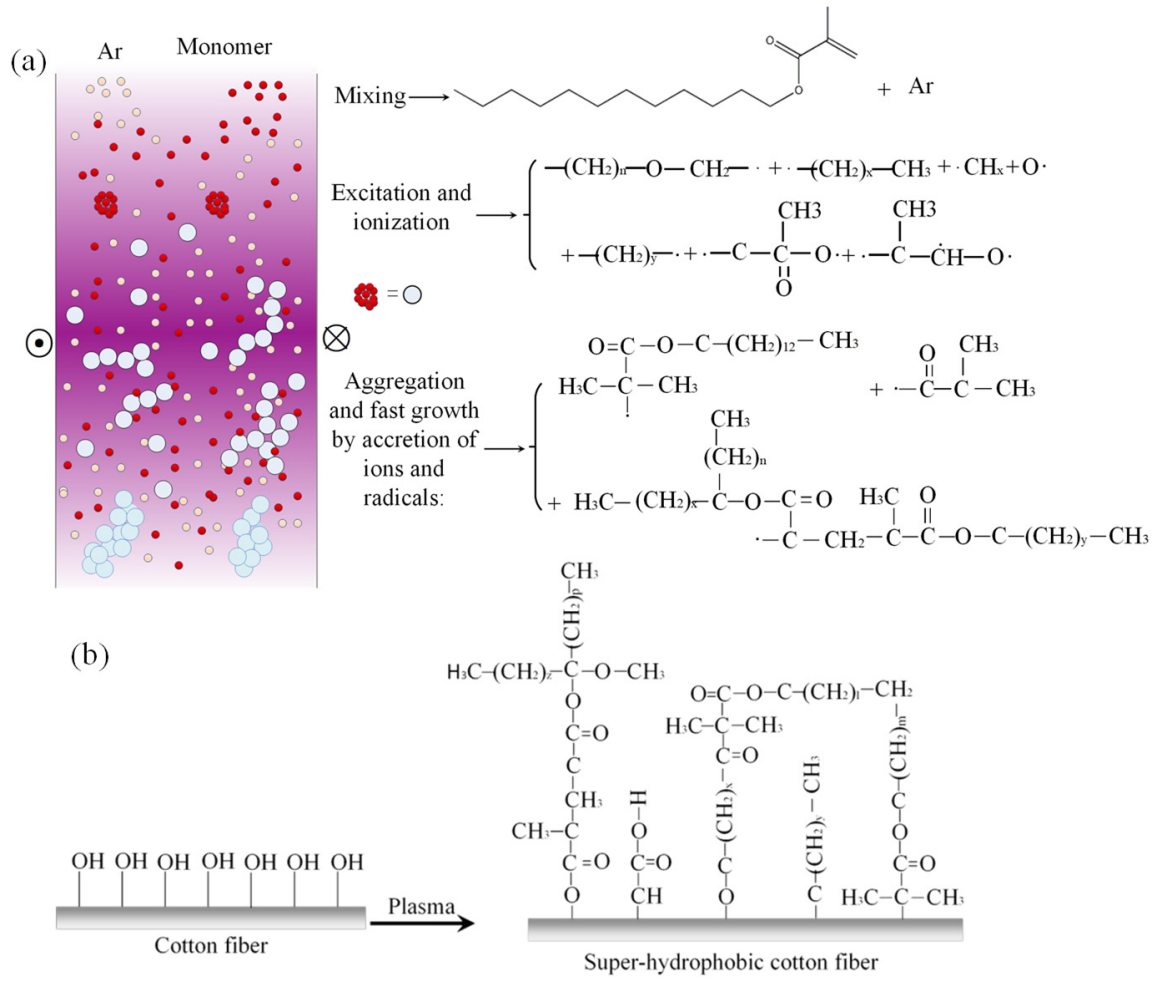

Figure 6. Schematic diagram of the reaction mechanism in the plasma chamber: (a) LMA monomer; (b) cotton fabric surface.

\section{Conclusions}

In this paper, the effect of electron temperatures in ICP at different process positions and gas pressures on the super-hydrophobicity of cotton fabrics was investigated. It was found that the main reactive processes responsible for increasing the hydrophobicity of the cotton surface after plasma treatment were the deposition of alkyl and ester groups. The best hydrophobicity of the sample surface $\left(\mathrm{WCA}=160.95^{\circ}, \mathrm{SA}=9.65^{\circ}\right)$ was obtained with an electron temperature of $4.64 \mathrm{eV}$ at a process position of $38 \mathrm{~mm}$. When the process position was $55 \mathrm{~mm}$, the cotton fabric surface achieved the worst hydrophobicity (WCA $=41.89^{\circ}$, without SA value). The super-hydrophobic property of the cotton fabric was achieved by the induction of the alkyl and ester groups and the formation of the micro-nano-structure. The radicals in the chamber induced graft reactions on the cotton fiber surface and free radical polymerization of the LMA monomers, which greatly enhanced the bond between the fiber and coating layer and the intensity of the layer. Further, the micro-nano-structure was synthesized by the micro-structure of the cotton fabric itself and the nanoparticles and nano-grooves on the surface of the cotton fabric, which were induced by the plasma treatment. In this research, the correlation between the electron temperature in the ICP reaction chamber and the effects on the material surface treatment was investigated, which provides a good reference for the selection of parameters in the industrial plasma surface modification process.

Supplementary Materials: The following are available online at http://www.mdpi.com/2079-6412/10/2/160/s1. Video S1: Repellency to flow water of Cotton-g-LMA fabrics.

Author Contributions: Y.G., R.Z. and J.Y. contributed to the project management, L.X., Y.L. and L.L. contributed to the experiment and characterization of the Cotton-g-LMA fabrics; L.X., X.C., L.L., J.S. and L.Y. contributed to the measurement of the electron temperature. All authors have read and agreed to the published version of the manuscript.

Funding: This research was funded by the Natural Science Foundation of China (Grant Nos. 11875104, 11475043 and 11705115), and the National Key R\&D Program of China (Project No.2017YFB0309100). 
Acknowledgments: The authors would like to thank Xiaojiang Huang of the College of Science, Donghua University for his valuable comments and guidance throughout this study.

Conflicts of Interest: The authors declare no conflict of interest.

\section{References}

1. Xu, L.H.; Zhuang, W.; Xu, B.; Cai, Z.S. Fabrication of super-hydrophobic cotton fabrics by silica hydrosol and hydrophobization. Appl. Surf. Sci. 2011, 257, 5491-5498. [CrossRef]

2. Lin, D.M.; Zeng, X.R.; Li, H.Q.; Lai, X.J. Facile fabrication of super-hydrophobic and flame-retardant coatings on cotton fabrics via layer-by-layer assembly. Cellulose 2018, 25, 3135-3149. [CrossRef]

3. Przybylak, M.; Maciejewski, H.; Dutkiewicz, A.; Dabek, I.; Nowicki, M. Fabrication of super-hydrophobic cotton fabrics by a simple chemical modification. Cellulose 2016, 23, 2185-2197. [CrossRef]

4. Chen, D.Z.; Chen, F.X.; Zhang, H.W.; Yin, X.Z.; Zhou, Y.S. Preparation and characterization of novel hydrophobic cellulose fabrics with polyvinylsilsesquioxane functional coatings. Cellulose 2016, 23, 941-953. [CrossRef]

5. Barati Darband, G.; Aliofkhazraei, M.; Khorsand, S.; Sokhanvar, S.; Kaboli, A. Science and Engineering of Super-hydrophobic Surfaces: Review of Corrosion Resistance, Chemical and Mechanical Stability. Arab. J. Chem. 2018. [CrossRef]

6. Barthlott, W.; Neinhuis, C. Purity of the sacred lotus, or esCape from contamination in biological surfaces. Planta 1997, 202, 1-8. [CrossRef]

7. Xu, L.; Deng, J.; Guo, Y.; Wang, W.; Zhang, R.; Yu, J. Fabrication of super-hydrophobic cotton fabric by low-pressure plasma-enhanced chemical vapor deposition. Text. Res. J. 2019, 89, 1853-1862. [CrossRef]

8. Peixoto, T.; Pereira, F.; Silva, P.L.; Guedes, R.M. Fibrous structures in augmentation for rotator cuff repair: An experimental comparison. Biomed. Phys. Eng. Express 2018, 4, 045021. [CrossRef]

9. Wu, M.; Ma, B.; Pan, T.; Chen, S.; Sun, J. Silver-Nanoparticle-Colored Cotton Fabrics with Tunable Colors and Durable Antibacterial and Self-Healing Super-hydrophobic Properties. Adv. Funct. Mater. 2016, 26, 569-576. [CrossRef]

10. Xu, Q.B.; Ke, X.T.; Shen, L.W.; Ge, N.Q.; Zhang, Y.Y.; Fu, F.Y.; Liu, X.D. Surface modification by carboxymethy chitosan via pad-dry-cure method for binding Ag NPs onto cotton fabric. Int. J. Biol. Macromol. 2018, 111, 796-803. [CrossRef]

11. Meikandan, M.; Malarmohan, K. Fabrication of a Super-hydrophobic Nanofibres by Electrospinning. Dig. J. Nanomater. Biostructures 2017, 12, 11-17.

12. Jiang, C.; Liu, W.Q.; Yang, M.P.; He, S.; Xie, Y.K.; Wang, Z.F. Synthesis of super-hydrophobic fluoro-containing silica sol coatings for cotton textile by one-step sol-gel process. J. Sol Gel Sci. Technol. 2018, 87, 455-463. [CrossRef]

13. Airoudj, A.; Bally-Le Gall, F.; Roucoules, V. Textile with Durable Janus Wetting Properties Produced by Plasma Polymerization. J. Phys. Chem. C 2016, 120, 29162-29172. [CrossRef]

14. Wang, Z.; Yang, W.; Sun, F.; Zhang, P.; He, Y.; Wang, X.; Luo, D.; Ma, W.; Sergio, G.-C. Construction of a super-hydrophobic coating using triethoxyvinylsilane-modified silica nanoparticles. Surf. Eng. 2018, 35, 418-425. [CrossRef]

15. Bryuzgin, E.; Klimov, V.; Zaytsev, S.; Navrotskiy, A.; Novakov, I. Influence of the Structure of Glycidyl Methacrylate Copolymers on the Hydrophobic Properties of Cellulose Materials. Adv. Mater. Res. 2015, 1098, 98-103. [CrossRef]

16. Karaman, M.; Yenice, E. Plasma Enhanced Chemical Vapor Deposition of Poly(2,2,3,4,4,4-hexafluorobutyl acrylate) Thin Films. Chem. Vap. Depos. 2015, 21, 188-195. [CrossRef]

17. Iizuka, S.; Koizumi, T.; Takada, T.; Sato, N. Effect of electron temperature on negative hydrogen ion production in a low-pressure Ar discharge plasma with methane. Appl. Phys. Lett. 1993, 63, 1619-1621. [CrossRef]

18. Karakas, E.; Donnelly, V.M.; Economou, D.J. Abrupt transitions in species number densities and plasma parameters in a CH3F/O2 inductively coupled plasma. Appl. Phys. Lett. 2013, 102, 2354-2357. [CrossRef]

19. Sasaki, H.; Nanbu, K.; Takahashi, M. Measurement of plasma parameters in an inductively coupled plasma reactor. Aip. Conf. Proc. 2001, 585, 262-269. 
20. Li, H.; Liu, Y.; Zhang, Y.R.; Gao, F.; Wang, Y.N. Nonlocal electron kinetics and spatial transport in radio-frequency two-chamber inductively coupled plasmas with argon discharges. J. Appl. Phys. 2017, 121. [CrossRef]

21. Lee, Y.S.; In, J.H.; Ahn, S.K.; Seo, S.H.; Chang, H.Y.; You, D.J.; Ahn, S.W.; Lee, H.M. The trend of electron temperature and electron density in the process of microcrystalline silicon solar cells. Curr. Appl. Phys. 2010, 10, S234-S236. [CrossRef]

22. Li, X.M.; Lin, J.; Qiu, Y.P. Influence of He/O2 atmospheric pressure plasma jet treatment on subsequent wet desizing of polyacrylate on PET fabrics. Appl. Surf. Sci. 2012, 258, 2332-2338. [CrossRef]

23. Li, Y.Q.; Zhang, Y.; Zou, C.; Shao, J.Z. Study of plasma-induced graft polymerization of stearyl methacrylate on cotton fabric substrates. Appl. Surf. Sci. 2015, 357, 2327-2332. [CrossRef]

24. Qu, M.; Liu, S.; He, J.; Feng, J.; Yao, Y.; Hou, L.; Ma, X.; Liu, X. Fabrication of recyclable superhydrophobic materials with self-cleaning and mechanically durable properties on various substrates by quartz sand and polyvinylchloride. Rsc. Adv. 2016, 6, 79238-79244. [CrossRef]

25. Yang, L. Wettability and Adhesive Properties of Polymers by RF Plasma Modification. Ph.D. Thesis, Dalian University of Technology, Dalian, China, 2010.

26. Quitzau, M.; Wolter, M.; Zaporojtchenko, V.; Kersten, H.; Faupel, F. Modification of polyethylene powder with an organic precursor in a spiral conveyor by hollow cathode glow discharge. Eur. Phys. J. D 2010, 58, 305-310. [CrossRef]

(C) 2020 by the authors. Licensee MDPI, Basel, Switzerland. This article is an open access article distributed under the terms and conditions of the Creative Commons Attribution (CC BY) license (http://creativecommons.org/licenses/by/4.0/). 